\title{
Bone Metabolism Parameters in Hemodialysis Patients With Chronic Kidney Disease and in Patients After Kidney Transplantation
}

\author{
M. MARCHELEK-MYŚLIWIEC ${ }^{1}$, V. DZIEDZIEJKO ${ }^{2}$, M. NOWOSIAD-MAGDA ${ }^{3}$, \\ M. WIŚNIEWSKA ${ }^{1}$, K. SAFRANOW ${ }^{2}$, A. PAWLIK ${ }^{4}$, L. DOMAŃSKI ${ }^{1}$, K. DOLEGGOWSKA ${ }^{1}$, \\ B. DOLĘGOWSKA ${ }^{3}$, J. STĘPNIEWSKA ${ }^{1}$, K. CIECHANOWSKI ${ }^{1}$
}

${ }^{1}$ Clinical Department of Nephrology, Transplantology and Internal Medicine, Pomeranian Medical University, Szczecin, Poland, ${ }^{2}$ Department of Biochemistry and Medical Chemistry, Pomeranian Medical University, Szczecin, Poland, ${ }^{3}$ Department of Microbiology, Immunology and Laboratory Medicine, Pomeranian Medical University, Szczecin, Poland, ${ }^{4}$ Department of Physiology, Pomeranian Medical University, Szczecin, Poland

Received January 15, 2019

Accepted August 5, 2019

Epub Ahead of Print October 25, 2019

\begin{abstract}
Summary
Chronic kidney disease adversely affects the structure and metabolism of bone tissue, which may be a result of disturbed biochemical processes in adipose tissue. Renal replacement therapy is a life-saving therapy but it does not restore all metabolic functions and sometimes even escalates some disturbances. The study included 126 subjects: 47 hemodialysis patients (HD), 56 patients after renal transplantation ( $T x)$ and 23 healthy controls (K). Bone density at the femoral neck (FN) and lumbar spine (LS), as well as body composition (adipose tissue content and lean body mass) were measured in each patient using the DXA method. In addition, serum concentrations of glucose, calcium, phosphorus, parathormone, FGF23, Klotho, osteocalcin, leptin, adiponectin and 1,25-dihydroxyvitamin $D_{3}$ were measured. We observed significantly higher concentrations of leptin, FGF23 and Klotho proteins in the HD patients (77.2 $\pm 48.1 \mathrm{ng} / \mathrm{ml}, \quad 54.7 \pm 12.4 \mathrm{pg} / \mathrm{ml}, 420.6 \pm 303.8 \mathrm{ng} / \mathrm{ml}$, respectively) and the Tx group $(33.2 \pm 26.5 \mathrm{ng} / \mathrm{ml}$; $179.8 \pm 383.9 \mathrm{pg} / \mathrm{ml} ; 585.4 \pm 565.7$, respectively) compared to the control group $(24.4 \pm 24.6 \mathrm{ng} / \mathrm{ml}, 43.3 \pm 37.3 \mathrm{pg} / \mathrm{ml}, 280.5 \pm$ $376.0 \mathrm{ng} / \mathrm{ml}$ ). Significantly lower bone density at FN was observed in the HD and Tx patients in comparison to the controls and in the HD patients compared to the Tx group. There were no significant differences in body mass composition between the studied groups. The results of this study indicate that both hemodialysis and transplantation are associated with increased serum concentrations of leptin, FGF23 and Klotho proteins, as well as lower bone density at femoral neck.
\end{abstract}

\section{Key words}

Body composition • Bone metabolism parameters • Bone mineral density • Kidney failure

\section{Corresponding author}

A. Pawlik, Department of Physiology, Pomeranian Medical University, Powstańców Wlkp 72 Str, 70-111 Szczecin, Poland. E-mail: pawand@poczta.onet.pl

\section{Introduction}

Chronic kidney disease (CKD) negatively influences the quality of life of patients. Adverse changes affect many systems and tissues, including cardiovascular, bone, and hormonal, and escalate with the progression of the disease (Nasuto et al. 2016). According to previous studies, disturbances in calcium and phosphate have been proven to cause vascular sclerosis, rapid atherosclerosis progression and an increased risk of cardiovascular death in CKD patients (Bansal et al. 2017, Webster et al. 2017). Initial changes can be noticed in the early stages of CKD. The progression of the disease enhances these disorders and renal replacement therapy does not correct them (Maréchal et al. 2012). Recent studies indicate strong relationships between bone and fat metabolism. Adipokines released by adipose tissue, such as leptin and 
adiponectin, besides regulating appetite and carbohydrate metabolism, also influence bone tissue metabolism. On the other hand, proteins, such as osteocalcin, which are involved in bone tissue metabolim, play an important role in the regulation of carbohydrate metabolism (Bonnet 2017). Leptin is a hormone produced by adipocytes. Its multidirectional activity includes regulation of satiety by influencing the appetite, regulation of glycemic homeostasis, and insulin sensitivity. In CKD, the concentration of leptin increases with GFR (glomerular filtration rate) deterioration (Pedone et al. 2015). In hemodialysis patients, leptin was shown to be related to arterial stiffness and bone turnover (Kuo et al. 2018, Zoccali et al. 2004).

Adiponectin is also released by adipose tissue. It correlates negatively with nutritional state, reduces insulin resistance and shows the anti-inflammatory properties (Liu and Liu 2014). In hemodialysis males, adiponectin was associated with decreased bone density (Okuno et al. 2012). Rhee et al. showed that high adiponectin levels in hemodialyzed patients are associated with a higher risk of death (Rhee et al. 2015). Osteocalcin is a protein produced by osteoblasts and its synthesis is stimulated by vitamin D. It has affinity for hydroxyapatite and is involved in mineralization of bone tissue (Baumgrass et al. 1997). As recently shown, osteocalcin has been associated with insulin resistance (Vervloet et al. 2014). Experimental studies in animals have demonstrated its positive influence on reducing of glycaemia (Ferron et al. 2008).

FGF23 (fibroblast growth factor 23), similar to osteocalcin, is produced by osteoblasts. It is bound to the receptor for FGF (FGFR) with the $\alpha$ Klotho protein. The aKlotho/FGF23 complex blocks the expression of NaPi2a and $\mathrm{NaPi} 2 \mathrm{c}$ sodium-phosphate cotransporter in the proximal tubules and thereby inhibits reabsorption of phosphates (Courbebaisse and Lanske 2018). In CKD, the concentration of FGF23 increases with GFR deterioration as a response to hyperphosphatemia (Isakova et al. 2011). FGF23 levels correlated with inflammatory markers such as CRP and IL-6 (Munoz Mendoza et al. 2012). Elevated FGF23 levels are a risk factor for the progression of renal disease and death due to cardiovascular events, independently of serum phosphate levels (Gutiérrez et al. 2008). The synthesis of FGF23 is stimulated by vitamin D, while FGF23 inhibits the synthesis of vitamin D (Liu et al. 2006). Vitamin D is activated by renal $1 \alpha$-hydroxylase and is responsible for maintaining calcium-phosphate homeostasis by increasing calcium and phosphate absorption. Patients with CKD are affected by vitamin D deficiency, which has even been reported after successful kidney transplantation (Ewers et al. 2008). Low levels of vitamin $\mathrm{D}$ in hemodialyzed patients were reported to be associated with obesity and metabolic syndrome (Ahmadi et al. 2016). Also, Klotho and FGF23 proteins closely related to calcium-phosphate metabolism may be associated with insulin resistance (Kanbay et al. 2017).

Proteins, such as osteocalcin, leptin and adiponectin, play a dual role, being markers of bone metabolism as well as carbohydrate metabolism. Currently, their importance in kidney diseases is not fully understood.

The aim of this study was to examine the concentrations of adipokines, osteocalcin, Klotho and FGF23 in CKD patients on hemodialysis and patients after kidney transplantation, as well as to investigate their relationship with other metabolic parameters, body composition and bone density.

\section{Material and Methods}

The study included 126 subjects: 47 CKD patients (13 female and 34 male) treated with hemodialysis (HD), 56 patients ( 23 female and 33 male) after kidney transplantation (Tx), and 23 healthy subjects (13 female and 10 male) as the control group (K). Inclusion criteria for the control group were: aged over 18 years, glomerular filtration (GFR) above $60 \mathrm{ml} / \mathrm{min} /$ $1.73 \mathrm{~m}^{2}$, lack of chronic inflammatory diseases (lupus or rheumatoid arthritis) and osteoporosis. For the HD group, the inclusion criteria were: aged over 18 years, receiving renal replacement therapy for at least 12 months and less than 5 years at qualification, treatment with constant doses of the active vitamin D (alfadiol), (four patients received additionally cinacalcet), calcium preparations and heparin, and on hemodialysis for the last 3 months before inclusion, and $\mathrm{Kt} / \mathrm{V}$ above 1.2. All HD patients with diabetes were treated with insulin. The inclusion criteria for renal transplant patients were: kidney transplantation at least 2 years prior to qualification, stable doses of immunosuppressive drugs over the last 3 months, standard immunosuppression with calcineurin inhibitor, mycophenolate mofetil, corticosteroids. Patients after renal transplantation with diagnosed diabetes (11 subjects) were treated with insulin (4 subjects) or with sulphonylurea derivatives (7 subjects). The Subjects diagnosed with cancer and 
osteoporosis before entering the study or treated with heparin or anticoagulants were excluded from the study. All participants provided written informed consent. This study was approved by the Bioethical Commission at the Pomeranian Medical University and was performed in accordance with the guidelines proposed in Declaration of Helsinki (2000) of the World Medical Association.

The etiology of CKD in HD patients was as follows: diabetes mellitus (DM) 9 subjects, hypertension (HA) 8, autosomal dominant polycystic kidney disease (ADPKD) 2, glomerulonephritis (GN) 7, and other 21. In the kidney graft recipient group, etiology was: DM 5 subjects, HA 11, ADPKD 6, GN 16, and other 18.

Densitometric examination of bone density at the femoral neck (FN) and lumbar spine (LS) regions, as well as of body composition was performed using dual X-ray absorptiometry (DXA; Lunar Prodigy Advance,
GE Healthcare). Measurements of bone density (BMD; $\mathrm{g} / \mathrm{cm}^{2}$ ) were expressed as a T-score according to the WHO guidelines, and body composition measurements as mass of body fat or lean tissue in kilograms $(\mathrm{kg})$.

Fasting blood samples were collected from the peripheral vein in the $\mathrm{K}$ and $\mathrm{Tx}$ groups for biochemical analysis (using Sarstedt S-Monovette tubes with clotting activator). In the HD patients, blood samples were collected before a hemodialysis procedure.

Standard biochemical parameters were assessed by spectrophotometry using an Architect 800 biochemistry analyser (Abbott Diagnostics, USA). eGFR was estimated using the CKD-EPI equation. Serum concentrations of 1,25-dihydroxyvitamin $\mathrm{D}_{3}$, leptin, adiponectin, osteocalcin, FGF23 and Klotho protein examined in the study were determined by the ELISA method using commercially available kits.

Table 1. Characteristics of the studied groups presenting selected biochemical parameters of lipid, carbohydrate, and calciumphosphate metabolism, as well as bone density, and body composition.

\begin{tabular}{|c|c|c|c|c|c|c|}
\hline Parametes & $\begin{array}{c}\mathbf{K} \\
\operatorname{Mean} \pm \mathbf{S D}\end{array}$ & $\begin{array}{c}\text { HD } \\
\text { Mean } \pm \text { SD }\end{array}$ & $\begin{array}{c}\text { Tx } \\
\operatorname{Mean} \pm \text { SD }\end{array}$ & $\begin{array}{c}\text { HD } \\
\text { vs } \\
\text { K } \\
\end{array}$ & $\begin{array}{l}\text { Tx } \\
\text { vs } \\
\text { K } \\
\end{array}$ & $\begin{array}{c}\text { Tx } \\
\text { vs } \\
\text { HD }\end{array}$ \\
\hline & $\mathbf{n}=\mathbf{2 3}$ & $n=47$ & $n=56$ & & $\mathbf{p}^{*}$ & \\
\hline Age (years) & $53.8 \pm 13.2$ & $59.1 \pm 14.5$ & $55.0 \pm 12.4$ & 0.09 & 0.74 & 0.07 \\
\hline $\operatorname{GFR}\left(\mathrm{ml} / \mathrm{min} / 1.73 \mathrm{~m}^{2}\right)$ & $91.1 \pm 17.1$ & - & $56.6 \pm 22.8$ & $<0.001$ & $<0.001$ & $<0.001$ \\
\hline Glucose (mmol/l) & $5.35 \pm 1.17$ & $6.20 \pm 1.77$ & $5.53 \pm 1.08$ & 0.01 & 0.13 & 0.04 \\
\hline Cholesterol (mg/dl) & $182.9 \pm 23.7$ & $200.8 \pm 30.8$ & $189.8 \pm 35.3$ & 0.02 & 0.39 & 0.13 \\
\hline Triacylglycerols $(\mathrm{mg} / \mathrm{dl})$ & $163.9 \pm 35.7$ & $186.8 \pm 55.4$ & $174.1 \pm 41.8$ & 0.02 & 0.30 & 0.06 \\
\hline Calcium $(\mathrm{mmol} / \mathrm{l})$ & $2.34 \pm 0.26$ & $2.26 \pm 0.18$ & $2.29 \pm 0.14$ & 0.30 & 0.90 & 0.06 \\
\hline Phosphorus (mmol/l) & $1.55 \pm 0.20$ & $1.91 \pm 0.40$ & $1.51 \pm 0.22$ & $<0.001$ & 0.27 & $<0.001$ \\
\hline Leptin $(n g / m l)$ & $24.4 \pm 24.6$ & $77.2 \pm 48.1$ & $33.2 \pm 26.5$ & $<0.001$ & 0.12 & $<0.001$ \\
\hline Adiponectin $(u g / m l)$ & $11.9 \pm 6.4$ & $15.7 \pm 9.5$ & $15.7 \pm 8.3$ & 0.25 & 0.07 & 0.61 \\
\hline Parathyroid hormone (pg/ml) & $48.8 \pm 30.7$ & $423.1 \pm 271.3$ & $100.9 \pm 77.0$ & $<0.001$ & $<0.001$ & $<0.001$ \\
\hline Osteocalcin $(\mathrm{ng} / \mathrm{ml})$ & $6.3 \pm 1.8$ & $39.8 \pm 15.2$ & $15.7 \pm 7.8$ & $<0.001$ & $<0.001$ & $<0.001$ \\
\hline$F G F 23(\mathrm{pg} / \mathrm{ml})$ & $43.3 \pm 37.3$ & $54.7 \pm 12.4$ & $179.8 \pm 383.9$ & 0.04 & $<0.001$ & $<0.001$ \\
\hline Klotho protein $(\mathrm{ng} / \mathrm{ml})$ & $280.5 \pm 376.0$ & $420.6 \pm 303.8$ & $585.4 \pm 565.7$ & 0.007 & 0.01 & 0.51 \\
\hline $1,25(\mathrm{OH})_{2}$ Vitamin $D_{3}(\mathrm{pg} / \mathrm{ml})$ & $49.8 \pm 47.8$ & $53.6 \pm 41.8$ & $72.9 \pm 51.9$ & 0.73 & 0.01 & 0.046 \\
\hline$B M I\left(\mathrm{~kg} / \mathrm{m}^{2}\right)$ & $26.6 \pm 4.1$ & $26.8 \pm 4.7$ & $26.8 \pm 4.0$ & 0.92 & 0.88 & 0.96 \\
\hline Lean mass ( $\mathrm{kg}$ ) & $48.2 \pm 11.3$ & $50.6 \pm 10.0$ & $49.6 \pm 11.6$ & 0.29 & 0.53 & 0.56 \\
\hline Body fat $(\mathrm{kg})$ & $27.7 \pm 6.8$ & $24.4 \pm 10.0$ & $24.9 \pm 7.4$ & 0.30 & 0.12 & 0.87 \\
\hline FN T-score & $-0.09 \pm 1.14$ & $-1.80 \pm 0.92$ & $-1.19 \pm 1.10$ & $<0.001$ & $<0.001$ & 0.006 \\
\hline LST-score & $0.02 \pm 1.40$ & $-0.79 \pm 1.87$ & $-0.56 \pm 1.65$ & 0.08 & 0.12 & 0.64 \\
\hline
\end{tabular}

Reference ranges for standard laboratory measurements: Glucose $<5.50(\mathrm{mmol} / \mathrm{l})$; Cholesterol $<200$ (mg/dl); Triacylglycerols < 150 (mg/dl); Calcium 2.15-2.50 (mmol/l); Phosphorus 0.74-1.52 (mmol/l); Parathyroid hormone 15.0-68.3 (pg/ml), * Mann-Whitney test, FN - femoral neck, LS - lumbar spine 


\section{Statistical analysis}

Since distributions of most biochemical parameters were significantly different from the normal distribution $(\mathrm{p}<0.05$; Shapiro-Wilk test), non-parametric tests were used for statistical analysis of quantitative variables. The Mann-Whitney test was used for comparisons between two groups and Spearman's rank correlation coefficient for assessment of associations between variables within groups. $\mathrm{P}<0.05$ without correction for multiple tests was considered as statistically significant.

\section{Results}

Characteristics of the studied groups, showing selected biochemical parameters of lipid, carbohydrate and calcium-phosphate metabolism, as well as bone density and body composition, are presented in Table 1 . There were no significant differences between the three groups as regards age and sex.

Serum concentrations of fasting glucose, total cholesterol, triglycerides, phosphorus, and leptin were significantly higher in the HD patients compared to the control group, while glucose, phosphorus, and leptin concentrations were higher in the HD patients compared to the Tx group. HD and Tx patients had significantly higher serum concentrations of PTH (parathormone), osteocalcin, FGF23 and Klotho protein compared to the control group. The Tx patients had significantly higher concentrations of 1,25-dihydroxyvitamin $\mathrm{D}_{3}$ compared to the controls and the HD patients (Table 1).

Results of densitometric examination indicated significantly lower FN bone density in HD and Tx patients compared to the controls and in HD patients compared to the Tx group. There were no statistically significant differences in LS bone density, and fatty tissue and lean mass between the studied groups (Table 1).

In the control group, Klotho protein concentrations showed a significant positive correlation with age and PTH levels and a significant negative correlation with GFR, fatty and lean body mass. 1,25-dihydroxyvitamin $\mathrm{D}_{3}$ concentrations presented a significant positive correlation with adiponectin concentration. PTH concentrations showed a significant positive correlation with age and Klotho protein concentrations and a significant negative correlation with GFR and fatty tissue mass.

In the HD patients, Klotho protein concentrations were significantly positively correlated with FGF23 and significantly negatively correlated with the leptin concentrations. 1,25-dihydroxyvitamin $\mathrm{D}_{3}$ concentrations significantly negatively correlated with FN and LS bone density and the PTH concentrations. The PTH concentrations were significantly positively

Table 2. Correlations of selected parameters in the group of hemodialyzed patients.

\begin{tabular}{|c|c|c|c|c|c|c|c|}
\hline \multirow[t]{2}{*}{ Parameter } & Klotho & FGF23 & Osteocalcin & $1,25(\mathrm{OH})_{2}$ Vit. $\mathrm{D}_{3}$ & PTH & Adiponectin & Leptin \\
\hline & \multicolumn{7}{|c|}{$\mathbf{R}_{\mathrm{S}}$} \\
\hline Age & 0.06 & -0.15 & -0.03 & -0.28 & -0.12 & -0.10 & -0.22 \\
\hline GFR & -0.21 & -0.15 & -0.35 & -0.02 & -0.13 & -0.10 & 0.09 \\
\hline$B M I$ & -0.03 & 0.04 & 0.22 & -0.02 & 0.12 & -0.12 & 0.44 \\
\hline$B O D Y F A T$ & -0.02 & 0.05 & 0.28 & -0.07 & 0.09 & -0.21 & 0.50 \\
\hline LEAN MASS & 0.01 & -0.004 & 0.04 & -0.24 & 0.57 & -0.53 & 0.23 \\
\hline FN T-score & 0.08 & -0.10 & 0.29 & -0.39 & 0.42 & -0.13 & 0.00 \\
\hline$L S T$-score & -0.02 & -0.15 & 0.30 & -0.57 & 0.38 & -0.26 & 0.09 \\
\hline Leptin & -0.30 & -0.24 & 0.01 & 0.22 & 0.18 & -0.16 & \\
\hline Adiponectin & 0.11 & 0.10 & 0.02 & 0.11 & -0.47 & & \\
\hline$P T H$ & -0.13 & -0.09 & 0.04 & -0.32 & & & \\
\hline $1,25(\mathrm{OH})_{2}$ Vit. $D_{3}$ & -0.06 & 0.04 & -0.13 & & & & \\
\hline Osteocalcin & 0.20 & 0.18 & & & & & \\
\hline$F G F 23$ & 0.31 & & & & & & \\
\hline
\end{tabular}

Statistically significant values have been bolded $(p<0.05), R_{s}$ - Spearman rank correlation coefficient, FN - femoral neck, LS - lumbar spine 
Table 3. Correlations between selected parameters in the group of patients after kidney transplantation.

\begin{tabular}{|c|c|c|c|c|c|c|c|}
\hline \multirow[t]{2}{*}{ Parameter } & Klotho & FGF23 & Osteocalcin & $1,25(\mathrm{OH})_{2}$ Vit. $\mathrm{D}_{3}$ & PTH & Adiponectin & Leptin \\
\hline & \multicolumn{7}{|c|}{$\mathbf{R}_{\mathrm{S}}$} \\
\hline Age & 0.12 & -0.004 & -0.18 & 0.04 & 0.16 & 0.25 & 0.06 \\
\hline GFR & -0.07 & -0.09 & -0.21 & 0.07 & -0.27 & -0.25 & -0.03 \\
\hline$B M I$ & -0.05 & -0.11 & -0.17 & 0.07 & 0.32 & -0.06 & 0.30 \\
\hline$B O D Y F A T$ & 0.03 & -0.04 & -0.15 & 0.10 & 0.31 & -0.03 & 0.54 \\
\hline$L E A N M A S S$ & -0.21 & -0.14 & -0.15 & -0.06 & 0.08 & -0.33 & -0.19 \\
\hline FN T-score & -0.08 & 0.08 & 0.11 & -0.003 & -0.34 & -0.22 & -0.07 \\
\hline$L S T$-score & -0.08 & -0.08 & -0.08 & -0.02 & -0.01 & -0.17 & 0.07 \\
\hline Leptin & -0.39 & 0.14 & 0.13 & 0.04 & 0.16 & -0.30 & \\
\hline Adiponectin & 0.43 & 0.08 & -0.22 & 0.11 & 0.04 & & \\
\hline PTH & 0.21 & 0.02 & 0.23 & -0.06 & & & \\
\hline $1,25(\mathrm{OH})_{2}$ Vit. $D_{3}$ & 0.19 & 0.16 & -0.14 & & & & \\
\hline Osteocalcin & -0.17 & 0.29 & & & & & \\
\hline$F G F 23$ & -0.04 & & & & & & \\
\hline
\end{tabular}

Statistically significant values have been bolded $(p<0.05), R_{S}$ - Spearman rank correlation coefficient, FN - femoral neck, LS - lumbar spine

correlated with lean body mass FN and LS bone density and significantly negatively correlated with adiponectin concentrations. Osteocalcin concentrations showed a negative correlation with eGFR and a positive correlation with LS bone density. Adiponectin negatively correlated with lean body mass. Leptin positively correlated with BMI and fat body mass (Table 2).

In the kidney recipients (Tx group), we observed a negative correlation between Klotho protein and leptin concentrations and a positive correlation with the adiponectin concentrations. The FGF23 concentrations were positively correlated only with osteocalcin concentrations. The PTH concentrations were negatively correlated with e-GFR and FN bone density, but positively with BMI. Concentrations of leptin showed a significant positive correlation with BMI and body fat, and negative correlation with the adiponectin concentrations. Adiponectin concentrations were significantly negatively correlated with lean body mass (Table 3 ).

\section{Discussion}

In this study, we examined the bone metabolism parameters in hemodialysis patients with chronic kidney disease and in patients after kidney transplantation. We assessed serum concentrations of adipokines, osteocalcin, Klotho and FGF23, and investigated their correlation with other metabolic parameters, body composition and bone density.

Previous studies have indicated that bone density decreases with the progression of CKD (West et al. 2015). Unfortunately, kidney transplantation does not significantly restore normal bone tissue metabolism (Pérez-Sáez et al. 2017). It has been shown that bone density is influenced, not only by agents that are directly involved in the regulation of calcium-phosphate homeostasis, but also by adipokines produced by adipose tissue, such as leptin and adiponectin. Previous studies reported that high concentrations of adiponectin were negatively correlated with bone density (Naot et al. 2017). Recent animal studies confirmed the ability of adiponectin to reduce Klotho secretion by renal tubular cells and, therefore, confirmed the influence of adiponectin on the regulation of bone mass (Rutkowski et al. 2017). Leptin can directly stimulate bone cells to form bone tissue (Cornish et al. 2002). However, by acting on the hypothalamus and activating the sympathetic system, leptin can also inhibit bone formation (Hamrick and Ferrari 2008).

In our study, only osteocalcin concentrations correlated positively with bone density in the LS spine segment in the HD group. Canoz et al. reported that $70 \%$ of 100 eligible renal transplant patients showed reduced bone density in the $\mathrm{FN}$ and $\mathrm{LS}$ regions (Canoz et al. 2015). We observed that the FN bone density differed significantly between the studied groups. It was lower in 
the HD patients than in the Tx group. In turn, bone density in the LS region did not show significant differences between the studied groups.

The increase in GFR after kidney transplantation did not reduce concentrations of FGF23 and Klotho, which were highest in this group. FGF23 is a phosphaturic hormone and, in CKD patients, its concentration increases with decrease in GFR (Gutierrez et al. 2005). High FGF23 levels have been shown to be associated with higher mortality in CKD, HD and Tx patients (Wolf 2012, Wolf et al. 2011). Patients with a renal transplant often present parathyroid hormone dysfunction associated with persistent secondary hyperparathyroidism. The lack of restoration of normal function in parathyroid cells can be explained by their long life (about 20 years), which leads to persistently higher FGF23 concentrations (Parfitt 1997). Klotho protein concentrations were highest in the Tx group. Liu et al. showed that Klotho levels were lower in patients with advanced renal disease compared to those with higher GFR. Cox regression analysis revealed that low Klotho protein concentrations were an independent risk factor for the progression of renal disease (Liu et al. 2018). In the study by Tan et al. of patients just before and a few months after a kidney transplantation, it was observed that Klotho concentrations decreased during the first week after a transplantation and then increased. The reasons for this phenomenon are currently unknown. Tan et al. showed that Klotho concentrations were not related to the reduction of immunosuppression or to biochemical blood parameters, and, therefore, suggested non-renal related causes of the increased Klotho concentrations (Tan et al. 2017). In our study, we also found the Klotho concentrations to be highest in patients after kidney transplantation. Analysis of relationship between Klotho and adipose tissue showed that, in the control group, Klotho levels negatively correlated with adipose tissue mass and lean body mass. These correlations were not observed in other studied groups. However, in the HD and Tx groups, the Klotho concentrations correlated negatively with leptin, while in the Tx group there was a positive correlation with adiponectin.

We did not demonstrate correlation of FGF23 with adipose tissue or adipokines. Montford et al., in a study conducted in dialyzed patients, confirmed the association of higher FGF23 concentrations with lower BMI and dyslipidemia (Montford et al. 2013). However, in a study conducted in subjects without kidney disease, FGF23 was elevated in obese subjects (Hu et al. 2018).

We observed a negative correlation of adiponectin concentrations with lean body mass in both of the studied groups. A study by Rhee et al. demonstrated that high concentrations of adiponectin were associated with a higher mortality rate in hemodialysis patients (Rhee et al. 2015). It was noticed that the survival of CKD patients, including those subjected to hemodialysis, is positively related to the lean body mass (Kalantar-Zadeh et al. 2017). It seems likely that the negative correlation between adiponectin and lean body mass that was reported in our study is associated with this issue.

Unfortunately, our study has some limitations fasting blood samples were collected from the peripheral vein in the $\mathrm{K}$ and $\mathrm{Tx}$ groups for biochemical analysis, whereas in the HD patients, blood samples were collected before a hemodialysis procedure. Another limitation of this exploratory study was analysis of multiple correlations between parameters without corrections for multiple statistical tests. The statistical power of the study was too low to detect significant associations after e.g. Bonferroni correction. Therefore, further studies with greater numbers of subjects should be performed to verify the results of the current study.

The results of this study indicate that both hemodialysis and transplantation is associated with the increase of leptin, FGF23 and Klotho proteins serum concentrations as well as lower bone density at femoral neck.

\section{Conflict of Interest}

There is no conflict of interest.

\section{Acknowledgements}

The study was financed by the grant of the National Science Center NN402564040.

\section{References}

AHMADI F, DAMGHANI S, LESSAN-PEZESHKI M, RAZEGHI E, MAZIAR S, MAHDAVI-MAZDEH M: Association of low vitamin D levels with metabolic syndrome in hemodialysis patients. Hemodial Int 20: 261-269, 2016. 
BANSAL N, KATZ R, ROBINSON-COHEN C, ODDEN MC, DALRYMPLE L, SHLIPAK MG, SARNAK MJ, SISCOVICK DS, ZELNICK L, PSATY BM, KESTENBAUM B, CORREA A, AFKARIAN M, YOUNG B, DE BOER IH: Absolute Rates of Heart Failure, Coronary Heart Disease, and Stroke in Chronic Kidney Disease: An Analysis of 3 Community-Based Cohort Studies. JAMA Cardiol 2: 314-318, 2017.

BAUMGRASS R, WILLIAMSON MK, PRICE PA: Identification of peptide fragment generated by digestion of bovine and human osteocalcin with lysosomal proteinases cathepsin B, D, L, H and S. Bone Miner Res 12: 447-455, 1997.

BONNET N: Bone-derived factors: a new gateway to regulate glycemia. Calcif Tissue Int 2: 174-183, 2017.

CANOZ MB, YAVUZ D, ALTUNOGLU A, YAVUZ R, COLAK T, HABERAL M: Successful Renal Transplantation, Bone Mineral Densitometry, and Affecting Factors. Transplant Proc 47: 1813-1819, 2015.

CORNISH J, CALLON KE, BAVA U, LIN C, NAOT D, HILL BL, GREY AB, BROOM N, MYERS DE, NICHOLSON GC, REID IR: Leptin directly regulates bone cell function in vitro and reduces bone fragility in vivo. J Endocrinol 175: 405-415, 2002.

COURBEBAISSE M, LANSKE B: Biology of Fibroblast Growth Factor 23: from physiology to pathology. Cold Spring Harb Perspect Med 8: pii: a031260. doi:10.1101/cshperspect.a031260, 2018.

EWERS B, GASBJERG A, MOELGAARD C, FREDERIKSEN AM, MARCKMANN P: Vitamin D status in kidney transplant patients: need for intensified routine supplementation. Am J Clin Nutr 87: 431-437, 2008.

FERRON M, HINOI E, KARSENTY G, DUCY P: Osteocalcin differentially regulates beta cell and adipocyte gene expression and affects the development of metabolic diseases in wild-type mice. Proc Natl Acad Sci U S A 105: 5266-5270, 2008.

GUTIERREZ O, ISAKOVA T, RHEE E, SHAH A, HOLMES J, COLLERONE G, JÜPPNER H, WOLF M: Fibroblast growth factor-23 mitigates hyperphosphatemia but accentuates calcitriol deficiency in chronic kidney disease. J Am Soc Nephrol 16: 2205-2215, 2005.

GUTIÉRREZ OM, MANNSTADT M, ISAKOVA T, RAUH-HAIN JA, TAMEZ H, SHAH A, SMITH K, LEE H, THADHANI R, JÜPPNER H, WOLF M: Fibroblast growth factor 23 and mortality among patients undergoing hemodialysis. N Engl J Med 359: 584-592, 2008.

HAMRICK MW, FERRARI SL: Leptin and the sympathetic connection of fat to bone. Osteoporos Int 7: 905-912, 2008.

HU X, MA X, LUO Y, XU Y, XIONG Q, PAN X, XIAO Y, BAO Y, JIA W: Associations of serum fibroblast growth factor 23 levels with obesity and visceral fat accumulation. Clin Nutr 37: 223-228, 2018.

ISAKOVA T, WAHL P, VARGAS GS, GUTIÉRREZ OM, SCIALLA J, XIE H, APPLEBY D, NESSEL L, BELLOVICH K, CHEN J, HAMM L, GADEGBEKU C, HORWITZ E, TOWNSEND RR, ANDERSON CA, LASH JP, HSU CY, LEONARD MB, WOLF M: Fibroblast growth factor 23 is elevated before parathyroid hormone and phosphate in chronic kidney disease. Kidney Int 79: 1370-1378, 2011.

KALANTAR-ZADEH K, RHEE CM, CHOU J, AHMADI SF, PARK J, CHEN JL, AMIN AN: The Obesity Paradox in Kidney Disease: How to Reconcile it with Obesity Management. Kidney Int Rep 2: 271-281, 2017.

KANBAY M, VERVLOET M, COZZOLINO M, SIRIOPOL D, COVIC A, GOLDSMITH D, SOLAK Y: Novel Faces of Fibroblast Growth Factor 23 (FGF23): Iron Deficiency, Inflammation, Insulin Resistance, Left Ventricular Hypertrophy, Proteinuria and Acute Kidney Injury. Calcif Tissue Int 100: 217-228, 2017.

KUO CH, LIN YL, LEE CJ, WANG CH, LAI YH, LIOU HH, HSU BG: Hyperleptinemia positively associated with central arterial stiffness in hemodialysis patients. PLoS One 13: e0190694, 2018.

LIU M, LIU F: Regulation of adiponectin multimerization, signaling and function. Best Pract Res Clin Endocrinol Metab 28: 25-31, 2014.

LIU QF, YE JM, YU LX, HE AL, SUN Q, HE DW, LI SS: Plasma s-Klotho is related to kidney function and predicts adverse renal outcomes in patients with advanced chronic kidney disease. J Investig Med 266: 669-675, 2018.

LIU S, TANG W, ZHOU J, STUBBS JR, LUO Q, PI M, QUARLES LD: Fibroblast growth factor 23 is a counterregulatory phosphaturic hormone for vitamin D. J Am Soc Nephrol 17: 1305-1315, 2006.

MARÉCHAL C, COCHE E, GOFFIN E, DRAGEAN A, SCHLIEPER G, NGUYEN P, FLOEGE J, KANAAN N, DEVUYST O, JADOUL M: Progression of coronary artery calcification and thoracic aorta calcification in kidney transplant recipients. Am J Kidney Dis 59: 258-269, 2012. 
MONTFORD JR, CHONCHOL M, CHEUNG AK, KAUFMAN JS, GREENE T, ROBERTS WL, SMITS G, KENDRICK J; HOST INVESTIGATORS: Low body mass index and dyslipidemia in dialysis patients linked to elevated plasma fibroblast growth factor 23. Am J Nephrol 37: 183-190, 2013.

MUNOZ MENDOZA J, ISAKOVA T, RICARDO AC, XIE H, NAVANEETHAN SD, ANDERSON AH, BAZZANO LA, XIE D, KRETZLER M, NESSEL L, HAMM LL, NEGREA L, LEONARD MB, RAJ D, WOLF M; CHRONIC RENAL INSUFFICIENCY COHORT: Fibroblast growth factor 23 and Inflammation in CKD. Clin J Am Soc Nephrol 7: 1155-1162, 2012.

NAOT D, MUSSON DS, CORNISH J: The activity of adiponectin in bone. Calcif Tissue Int 5: 486-499, 2017.

NASUTO M, PANSINI V, CORTET B, GUGLIELMI G, COTTEN A: Renal Failure: A Modern Semiology for an Old Disease. Semin Musculoskelet Radiol 20: 353-368, 2016.

OKUNO S, ISHIMURA E, NORIMINE K, TSUBONIWA N, KAGITANI S, YAMAKAWA K, YAMAKAWA T, SATO KK, HAYASHI T, SHOJI S, NISHIZAWA Y, INABA M: Serum adiponectin and bone mineral density in male hemodialysis patients. Osteoporos Int 23: 2027-2035, 2012.

PARFITT AM: The hyperparathyroidism of chronic renal failure: a disorder of growth. Kidney International 52: 3-9, 1997.

PEDONE C, ROSHANRAVAN B, SCARLATA S, PATEL KV, FERRUCCI L, INCALZI RA: Longitudinal association between serum leptin concentration and glomerular filtration rate in humans. PLoS One 10: e0117828, 2015.

PÉREZ-SÁEZ MJ, HERRERA S, PRIETO-ALHAMBRA D, NOGUÉS X, VERA M, REDONDO-PACHÓN D, MIR M, GÜERRI R, CRESPO M, DÍEZ-PÉREZ A, PASCUAL J: Bone Density, Microarchitecture, and Tissue Quality Long-term After Kidney Transplant. Transplantation 101: 1290-1294, 2017.

RHEE CM, NGUYEN DV, MORADI H, BRUNELLI SM, DUKKIPATI R, JING J, NAKATA T, KOVESDY CP, BRENT GA, KALANTAR-ZADEH K: Association of Adiponectin With Body Composition and Mortality in Hemodialysis Patients. Am J Kidney Dis 66: 313-321, 2015.

RUTKOWSKI JM, PASTOR J, SUN K, PARK SK, BOBULESCU IA, CHEN CT, MOE OW, SCHERER PE: Adiponectin alters renal calcium and phosphate excretion through regulation of klotho expression. Kidney Int 91: 324-337, 2017.

TAN SJ, CROSTHWAITE A, LANGSFORD D, OBEYSEKERE V, IERINO FL, ROBERTS MA, HUGHES PD, HEWITSON TD, DWYER KM, TOUSSAINT ND: Mineral adaptations following kidney transplantation. Transpl Int 30: 463-473, 2017.

VERVLOET MG, MASSY ZA, BRANDENBURG VM, MAZZAFERRO S, COZZOLINO M, UREÑA-TORRES P, BOVER J, GOLDSMITH D; CKD-MBD WORKING GROUP OF ERA-EDTA: Bone: a new endocrine organ at the heart of chronic kidney disease and mineral and bone disorders. Lancet Diabetes Endocrinol 2: 427-436, 2014.

WEBSTER AC, NAGLER EV, MORTON RL, MASSON P: Chronic Kidney Disease. Lancet 389: 1238-1252, 2017.

WEST SL, PATEL P, JAMAL SA: How to predict and treat increased fracture risk in chronic kidney disease. J Intern Med 278: 19-28, 2015.

WOLF M, MOLNAR MZ, AMARAL AP, CZIRA ME, RUDAS A, UJSZASZI A, KISS I, ROSIVALL L, KOSA J, LAKATOS P, KOVESDY CP, MUCSI I: Elevated fibroblast growth factor 23 is a risk factor for kidney transplant loss and mortality. J Am Soc Nephrol 22: 956-966, 2011.

WOLF M: Update on fibroblast growth factor 23 in chronic disease. Kidney Int 82: 737-747, 2012.

ZOCCALI C, PANUCCIO V, TRIPEPI G, CUTRUPI S, PIZZINI P, MALLAMACI F: Leptin and biochemical markers of bone turnover in dialysis patients. $J$ Nephrol 17: 253-260, 2004. 